\title{
DEVELOPMENT AND CLINICAL EVALUATION OF TOPICAL HYDROQUINONE NIOSOMAL GEL FORMULATION FOR THE TREATMENT OF MELASMA
}

\author{
AMAL A. AMMAR ${ }^{1}$, HODA A. SALEM ${ }^{2 *}$, SHEREEN A. ELADAWY ${ }^{1}$, ZINAB I. ABD ELSAMAD ${ }^{3}$, NEVEEN A. KOHAF ${ }^{1}$
}

1Department of Pharmaceutics and Industrial Pharmacy, Faculty of Pharmacy, Al-Azhar University, Egypt, ${ }^{2}$ Department of Clinical Pharmacy, Faculty of Pharmacy, Al-Azhar University, Egypt and Tabuk University, Saudi Arabia, ${ }^{3}$ Department of Dermatology and Venereology, Faculty of Medicine, Tanta University, Egypt

Email: hodasalem.pharmg@azhar.edu.eg

Received: 26 May 2020, Revised and Accepted: 20 Jun 2020

\section{ABSTRACT}

Objective: The goal of the present study was to develop niosomal gel as a nanocarrier for improved depigmentation effect of hydroquinone (HQ). As well as to evaluate the prepared niosomes for entrapment efficiency, transmission electron microscopy (TEM), zeta potential, and in vitro release study. As an ultimate point of the objectives was to evaluate the best-prepared niosomal gel formula clinically in well-diagnosed patients of melasma and the results were compared with a commercial product.

Methods: The effect of incorporation of co-surfactant such as Tween 20, Tween 40, and Tween 60 with Span 80, was studied to determine the highest entrapment efficiency and the desired release rate. Niosomes showed the highest entrapment efficiency was incorporated in different gelling agents like Carbopol 934 and Carboxymethylcellulose sodium (CMC Na) with different concentrations. Accelerated stability testing of HQ from niosomal gel formulations; the expiry date $t_{90}$ was estimated. The best-prepared niosomal gel formula was studied clinically in patients of melasma and the results were compared with the commercial product (Clearique 2\%) ${ }^{\circledR}$ Delta Pharma Company.

Results: There was a significant increase in the clinical efficacy of the niosomal therapy and a highly significant decrease regarding to modified melasma area and severity index (MASI), duration to achieve improvement, side effects, and the recurrence of melasma in patients treated with niosomal gel compared to the commercial product.

Conclusion: The incorporation of hydroquinone in niosomal gel improves its therapeutic effect regarding clinical effect, duration of treatment, side effects, recurrence and patient compliance.

Keywords: Hydroquinone, Niosomes, Niosomal gel, Surfactants, Co-surfactants, In vitro drug release study, Depigmentation effect

(C) 2020 The Authors. Published by Innovare Academic Sciences Pvt Ltd. This is an open access article under the CC BY license (http://creativecommons.org/licenses/by/4.0/) DOI: http://dx.doi.org/10.22159/ijap.2020v12i4.34304. Journal homepage: https://innovareacademics.in/journals/index.php/ijap

\section{INTRODUCTION}

Melasma is an acquired hyperpigmentary disorder on sunlight exposed skin of the face and neck, reported mainly among females with IV or V skin types. The etiology is unknown, but the most significant inclining factor is sun exposure. Other factors include pregnancy, contraceptives, race, hereditary factors and exogenous hormones $[1,2]$. Melasma presents as dark macules distributed bilaterally symmetrical, with serrated and irregular margins. The three major patterns of distribution are: Centro facial (cheeks, forehead, upper lip, nose and chin) in $65 \%$ of cases, malar (cheeks and nose) in $20 \%$ of cases and mandibular (rami of the mandible) in $15 \%$ of cases [3, 4]. Niosomes are non-ionic surfactant vesicles (NISVs) that have the ability to encapsulate hydrophilic drugs or partitioning lipophilic drugs into vesicular bilayer membranes [5]. Niosomes are microscopic unilamellar or multilamellar spheroid structures formed upon combining non-ionic surfactants with hydrated mixtures of cholesterol (Chol). The niosomes bilayer membrane has high compatibility with biological membranes giving them augmented stability and duration in circulation [6]. Niosomes have pulled in a lot of consideration in the delivery of dermal medications because of the numerous favorable circumstances like they are biodegradable, biocompatible, non-toxic, non-immunogenic in nature and effective in the variation of drug release properties [7, 8]. According to their size and structure, these vesicles can be administered by routes like intramuscular, intravenous, ocular, subcutaneous, oral, pulmonary, intraperitoneal, and transdermal $[9,10]$.

Hydroquinone (HQ), 1, 4-benzenediol, is a depigmenting agent. It is the frequently utilized compound in skin-toning preparations, which was reported to be effective at 1.5-2.0\%. Concentrations higher than $5.0 \%$ were liable to cause redness and burning. The depigmenting activity of HQ may partially be associated with the capability of the compound to act as an alternate substrate of tyrosinase; competing for tyrosine oxidation inactive melanocytes [11-13].

\section{MATERIALS AND METHODS}

\section{Materials}

HQ was a gift sample kindly supplied by Chemical Industrial Development Co., (CID) Giza, Egypt. Sorbitan mono-oleate (Span 80), Polyoxyethylene Sorbitan monolaurate (Tween 20), Polyoxyethylene Sorbitan monopalmitate (Tween 40), Polyoxyethylene Sorbitan monostearate (Tween 60), sodium sulfite, Carbopol 934, CMC Na, cholesterol, and cellulose membrane of the molecular weight cut off 10,000 were purchased from Sigma Chemical Co., Cairo, Egypt. Triethanolamine was purchased from Memphis Pharmaceutical Chemical Co. Egypt, CMC powder was purchased from El-Nasr Pharmaceutical Chemical Co. Egypt.

\section{Methods}

\section{Preparation of drug-loaded niosomes}

All HQ-entrapped niosomes were prepared from a mixture of nonionic surfactant, Chol and co-surfactant (table 1). The total lipid concentration was $300 \mu$ mole. Mixtures of Chol, with a nonionic surfactant (span80) and co-surfactant (Tween 20, Tween 40, and Tween 60 ) in 1:0.5:0.5 molar ratio were dissolved in $15 \mathrm{ml}$ chloroform in a $100 \mathrm{ml}$ rounded-bottom [14]. The organic solvent was removed at a temperature of $60^{\circ} \mathrm{C}$ under reduced pressure on a rotary evaporator to form a thin film on the flask wall. The excess organic solvent was then removed by leaving the flask in a desiccator under vacuum overnight. The obtained dried lipid film was hydrated with $5 \mathrm{ml}$ of phosphate buffer solution (PBS) (pH7.4) containing HQ $(2 \mathrm{mg} / \mathrm{ml})$ and $0.05 \%$ sodium sulfite as an antioxidant [15] by shaking with a mechanical shaker in a water bath at $60^{\circ} \mathrm{C}$ for about $1 \mathrm{~h}$. The resulting multilamellar non-ionic surfactant vesicle dispersion was then stored at less than $4{ }^{\circ} \mathrm{C}$ for congealing [16]. 
Table 1: Compositions of the prepared niosomal formulations

\begin{tabular}{|c|c|c|c|c|c|}
\hline Codes & Chol (mg) & Span 80 (mg) & Tween 20 (mg) & Tween 40 (mg) & Tween 60 (mg) \\
\hline F1 & 58.005 & 32.1 & 92 & - & - \\
\hline $\mathrm{F} 2$ & 58.005 & 32.1 & - & 96.2 & \\
\hline F3 & 58.005 & 32.1 & & - & 84.8 \\
\hline
\end{tabular}

Chol: cholesterol, all formulations contain $\mathrm{HQ}: 10 \mathrm{mg}, \mathrm{Na}_{2} \mathrm{So}_{3}: 0.05 \%$

\section{Characterization of the prepared noisome formulations}

\section{Morphology of formulated niosomal vesicles}

A drop of the dispersion was viewed under an optical microscope to observe the shape and lamellar nature of the vesicle. Photomicrographs were detected with a light microscope [17].

\section{Entrapment efficiency of drug-loaded niosomes}

The HQ-entrapped niosomes were separated from the unentrapped free drug by freeze-thawing/centrifugation method [18]. One ml samples of the prepared niosomal dispersions were frozen for $24 \mathrm{~h}$ at-20 ${ }^{\circ} \mathrm{C}$ in ependorf tubes. The frozen samples were removed from the freezer and centrifuged at 15,000 rpm for 10 min. Niosomal pellets were suspended in PBS (pH 7.4) and then centrifuged again. This washing step was repeated two times to ensure that an un-entrapped drug was no longer present in the void volume between the niosomes [18]. Supernatant was separated as it contains an unentrapped drug, which is highly soluble in PBS 7.4, using a micro-pipette. To the remaining pellet in the centrifuge tube, $500 \mu \mathrm{l}$ of $0.1 \mathrm{~N} \mathrm{NaOH}$ (as the drug is highly soluble in $0.1 \mathrm{~N} \mathrm{NaOH}$ ) was added and vortexed thoroughly for 3 min. After vortexing, a white suspension was obtained and $1 \mathrm{ml}$ of this suspension was taken with a micro-pipette and transferred to a test tube. To this $5 \mathrm{ml}$ methanol was added, which resulted in a clear solution; this was further vortexed in a vortex mixer for 2 min, such that to ensure that the niosomes are lysed completely to release the drug. This solution $(1 \mathrm{ml})$ was further diluted with methanol and filtered using membrane filter and the absorbance was determined using a UV spectrophotometer at $295 \mathrm{~nm}$ [19]. The entrapment efficiency (EE) is expressed as

$$
\% \mathrm{EE}=\frac{s a-s b}{s a} * 100
$$

$\mathrm{Sa}=$ Total amount of drug in the system, $\mathrm{Sb}=\mathrm{Amount}$ of drug in the supernatant after centrifugation [18].

\section{Transmission electron microscopy}

The prepared niosomal formulations with the highest entrapment efficiency were characterized for their morphology using TEM. To an aliquot of a suspension of prepared niosomal formulation, a sufficient quantity of $1 \%$ phosphor tungstic acid was added and mixed gently. A drop of the mixture was placed onto the carboncoated grid and drained off the excess. The grid was allowed to dry, and it was observed under TEM. Electron micrographs were taken at suitable magnification [17].

\section{Sizing of the vesicles}

NISVs were mounted on a glass slide and examined under a phasecontrast microscope with a magnification of $400 \mathrm{x}$ using a stage nanometer to determine the size of the vesicles.

\section{Zeta potential measurement}

Zeta potential of suitably diluted niosomal dispersion was determined using Zetasizer Nano ZS-90 at $25{ }^{\circ} \mathrm{C}$. The working principle of the instrument is electrophoretic light scattering (ELS), which determines the electrophoretic movement of charged particles under an applied electric field from the doppler shift of scattered light for zeta potential determination [20].

\section{In vitro release of HQ from niosomes}

The in vitro release of HQ from different niosomal formulations was carried out using a dissolution-dialysis apparatus, the cell of which was developed in our laboratory. The diffusion cell consists of a hollow plastic cylinder (length $20 \mathrm{~cm}$ and an internal diameter 3 $\mathrm{cm})$. After separation of the free drug, an accurately measured amount of HQ niosomal formulations, equivalent to $2 \mathrm{mg}$ of HQ was resuspended in $1 \mathrm{ml}$ PBS ( $\mathrm{pH} \mathrm{7.4)}$ ) and transferred to the diffusion cell to which a cellulose membrane of the molecular weight cut off 10,000 was attached to one side, and immersed in a receptor compartment containing $100 \mathrm{ml}$ PBS (pH 7.4). The temperature of the receptor compartment was maintained at $37{ }^{\circ} \mathrm{C} \pm 0.5{ }^{\circ} \mathrm{C}$. At the specified time interval for $24 \mathrm{~h}, 5 \mathrm{ml}$ samples were withdrawn from the receptor compartment, and the drug was determined spectrophotometrically at $\lambda_{\max } 295 \mathrm{~nm}$. Each sample withdrawn was replaced by an equal volume of PBS pH 7.4 [21].

The obtained results were compared with the In vitro release of plain drug using $2 \mathrm{mg}$ of HQ dissolved in $1 \mathrm{ml}$ PBS ( $\mathrm{pH} 7.4$ )

\section{Release kinetic evaluation}

Specific computer program was used to determine the kinetic parameters of the in vitro release of HQ from different niosomal formulations. Zero, and first-order kinetics as well as, Higuchi diffusion model, were tried-to choose the most suitable kinetic order or model for hydroquinone release.

\section{Preparation of HQ niosomal gels}

An equivalent amount of HQ niosomal formulations to get $2 \% \mathrm{w} / \mathrm{w}$ (drug/gel) separated from the un-entrapped drug was incorporated into the structured gels [22].

\section{Carbopol 934 and CMC Na were used as gelling bases \\ Preparation of carbopol 934 gel}

A Weighted amount of Carbopol 934 (1\%, 2\%, 3\% w/w) was dispersed in $100 \mathrm{ml}$ distilled water and stirred magnetically at a high speed. Stirring was continued until a thin dispersion, without lumps, was obtained, then the stirring speed was reduced to allow foam to break and to maintain a good liquid turnover while adding the $0.01 \% \mathrm{w} / \mathrm{w}$ of Triethanolamine required forming the gel [23].

\section{Preparation of CMC Na gel}

Weighed amount of CMC Na $(2 \%, 3 \%$ and $4 \% \mathrm{w} / \mathrm{w})$ powder was sprinkled, gently, on $100 \mathrm{ml}$ boiling distilled water and stirred magnetically at high speed. Stirring was continued until a thin hazy dispersion, without lumps, was formed. Leaving overnight in the refrigerator may be necessary for complete gel dispersion [24].

The plain drug gel was prepared in the same method, but instead of incorporation of niosome, the plain drug would be incorporated to the best gel base concentration regarding physical properties, in vitro drug release and patient compliance for comparison with niosomal gel.

\section{Evaluation of HQ niosomal gels}

\section{Colour, homogeneity and texture}

Colour, homogeneity and texture of the prepared niosomal gels were tested by visual examination.

\section{Determination of $\mathrm{pH}$}

$\mathrm{pH}$ of the prepared niosomal gel formulations was determined by digital a $\mathrm{pH}$ meter using the following method: one $\mathrm{g}$ of the gel was diluted with $9 \mathrm{~g}$ of distilled water and shaken well. The $\mathrm{pH}$ measurements were repeated three times for each formula and the reading was the average [25]. 
Table 2: Composition of different niosomal gel formulations

\begin{tabular}{|c|c|c|c|c|c|c|c|c|}
\hline \multirow[t]{3}{*}{ Codes } & \multicolumn{6}{|c|}{ Niosomal composition } & \multicolumn{2}{|c|}{ Gel bases \% w/w } \\
\hline & HQ & $\mathrm{Na}_{2} \mathrm{SO}_{3}$ & Chol & Span 80 & Tween 40 & Tween 60 & Carbopol 934 & CMC Na \\
\hline & & & (mg) & (mg) & (mg) & (mg) & $\%$ & $\%$ \\
\hline F2a1 & $2 \%$ & $0.05 \%$ & 58.005 & 32.1 & 96.2 & - & $1 \%$ & - \\
\hline $\mathrm{F} 2 \mathrm{a} 2$ & $2 \%$ & $0.05 \%$ & 58.005 & 32.1 & 96.2 & - & $2 \%$ & - \\
\hline F2a3 & $2 \%$ & $0.05 \%$ & 58.005 & 32.1 & 96.2 & - & $3 \%$ & - \\
\hline $\mathrm{F} 2 \mathrm{~b} 2$ & $2 \%$ & $0.05 \%$ & 58.005 & 32.1 & 96.2 & - & - & $2 \%$ \\
\hline F2b3 & $2 \%$ & $0.05 \%$ & 58.005 & 32.1 & 96.2 & - & - & $3 \%$ \\
\hline $\mathrm{F} 2 \mathrm{~b} 4$ & $2 \%$ & $0.05 \%$ & 58.005 & 32.1 & 96.2 & & - & $4 \%$ \\
\hline F3a1 & $2 \%$ & $0.05 \%$ & 58.005 & 32.1 & - & 84.8 & $1 \%$ & - \\
\hline F3a2 & $2 \%$ & $0.05 \%$ & 58.005 & 32.1 & - & 84.8 & $2 \%$ & - \\
\hline F3a3 & $2 \%$ & $0.05 \%$ & 58.005 & 32.1 & - & 84.8 & $3 \%$ & - \\
\hline F3b2 & $2 \%$ & $0.05 \%$ & 58.005 & 32.1 & - & 84.8 & - & $2 \%$ \\
\hline F3b3 & $2 \%$ & $0.05 \%$ & 58.005 & 32.1 & - & 84.8 & - & $3 \%$ \\
\hline F3b4 & $2 \%$ & $0.05 \%$ & 58.005 & 32.1 & - & 84.8 & - & $4 \%$ \\
\hline
\end{tabular}

\section{Spreadability test}

The spreadability of the formulated niosomal gels was measured by spreading $0.5 \mathrm{~g}$ of gel on a circle of $2 \mathrm{~cm}$ diameter pre-marked on a glass plate and then a second glass plate was employed [26]. A $5 \mathrm{~g}$ weight was permitted to rest on the upper glass plate for $5 \mathrm{~min}$ [27]. The diameter of the circle after spreading of the gels was determined.

\section{In vitro permeation through cellulose membrane}

Half g of each formulation containing $10 \mathrm{mg}$ of $\mathrm{HQ}$ was transferred to a dissolution cell to which a cellulose membrane of the molecular weight cut off 10,000 was attached to one side and the other side of the tube was attached to the stem of the dissolution apparatus and immersed in a beaker of the dissolution apparatus containing $100 \mathrm{ml}$ of PBS (pH 7.4). The temperature of the medium was maintained at $37 \pm 0.5{ }^{\circ} \mathrm{C}$. At specified time intervals for $24 \mathrm{~h}, 4 \mathrm{ml}$ samples were withdrawn, and the drug was determined spectrophotometrically at $\lambda_{\max } 295 \mathrm{~nm}$. Each sample withdrawn was replaced by an equal volume of PBS (pH 7.4).

\section{Accelerated stability testing}

The stability of HQ from niosomal gel formulations was studied using accelerated stability testing for $2 \mathrm{mo}$ at $4{ }^{\circ} \mathrm{C}, 25^{\circ} \mathrm{C}$, and $37^{\circ} \mathrm{C}$. The entrapment efficiency was measured after $7,14,21,30,45$ and $60 \mathrm{~d}$. Also; the expiry date t90 was estimated [28].

\section{Clinical evaluation of HQ niosomal gel formulation \\ Study design}

This study is a randomized prospective comparative controlled trial. It was carried out on Sixty Egyptian female patients with different clinical varieties of melasma. The patients were diagnosed clinically on the basis of the typical appearance of skin lesions and confirmed by Dermoscopic examination. The patients were selected from the Outpatient Clinic of Dermatology and Venereology Department, Tanta University Hospitals and the patients were identified by coded numbers to maintain privacy. The study was carried out after approval of the Medical Ethics Committee number 68 and written informed consent from patients. Patients were being randomized into two groups:

\section{The group I}

Thirty patients with melasma were treated topically with niosomal gel of HQ 2\% (span80: cholesterol: tween 40) in 2\% carbopol, which prepared in the laboratory of pharmaceutics and industrial pharmacy department, Faculty of Pharmacy (Girls branch)-Al-Azhar University. The gel was applied to the melasma lesions of the face once daily at night until a clinical cure or maximum of three months.

\section{The group II}

Thirty patients with melasma were treated with commercial topical HQ 2\% cream (Clearique 2\%) ®-Delta Pharma Company-Cairo-Egypt to the melasma lesions of the face once daily at night for the same duration as the other group of patients.

\section{Inclusion criteria}

Newly diagnosed cases, patients who didn't receive treatment for melasma in the previous $6 \mathrm{w}$ before starting the pharmacotherapy were eligible for this study. Patients who agreed to join the study and signed a written consent and continued till the end of the followup period were enrolled in the research.

\section{Exclusion criteria}

Pregnancy, miscarriage or nursing women, the use of hormonal therapy or contraceptive pills in the last 12 mo before the study and melasma patients who have systemic or other dermatological diseases were omitted from the research. Special emphasis on patients' occupations and exclusion of those with inevitable sun exposure and patients who did not complete the treatment or the follow-up.

\section{Methods} All the studied patients were subjected to a standard protocol
which consists of

Complete history taking for detailed clinical history; including the duration of the disease, evolution, precipitating or aggravating factors, any associated illness and previous treatment. General examinations to exclude patients with systemic diseases associated with hyperpigmentation as thyroid disease, Cushing's disease, adrenogenital syndrome, liver diseases, renal diseases and hypermelanosis of drug origin. Dermatological examination was done to exclude patients with skin diseases other than melasma and to evaluate the melasma lesions clinically.

Determination of modified melasma area and severity index (MASI) for clinical assessment of the patients' condition before and after therapy was scored as follows: Modified MASI score $=0.3 \mathrm{~A}(\mathrm{~F}) \mathrm{D}(\mathrm{F})+0.3 \mathrm{~A}(\mathrm{~lm}) \mathrm{D}(\mathrm{lm})+0.3 \mathrm{~A}$
$(\mathrm{rm}) \mathrm{D}(\mathrm{rm})+0.1 \mathrm{~A}(\mathrm{c}) \mathrm{D}(\mathrm{c})[29,30]$

(A) area of involvement and (D) darkness, with the (F) forehead, left malar region $(\mathrm{lm})$, right malar region $(\mathrm{rm})$, and chin (c), corresponding to $30 \%, 30 \%, 30 \%$ and $10 \%$ of the total face, respectively. The area of involvement in each of these 4 regions was given a numeric value of 0 to $6(0=$ no involvement; $1=<10 \% ; 2=10 \%-29 \% ; 3=30 \%-49 \% ; 4=$ $50 \%-69 \% ; 5=70 \%-89 \%$ and $6=90 \%-100 \%$ ).

Darkness was rated on a scale from 0 to $4(0=$ absent; $1=$ slight; $2=$ mild; $3=$ marked and $4=$ maximum). It was calculated by multiplying the value of the area of involvement by the severity rating for darkness, for each of the 4 facial regions. The range of the total score was from 0 to 24 [29].

\section{Digital photography registration}

Baseline photographs (frontal, right and left views) were taken for the face of every patient to document the pretreatment skin lesion and at the end of therapy and during follow up period to evaluate the clinical efficacy and safety of the treatment. 
The Fitzpatrick skin type is a commonly utilized framework to define a person's skin type in terms of reaction to ultraviolet radiation (UVR) exposure.

The current Fitzpatrick skin type classification indicates six different skin types, skin color, and reaction to sun exposure which varies from very fair (skin type I) to very dark (skin type VI) dependent on whether the patient burns at the first average sun exposure or tans at the first average sun exposure. The two primary variables that impact skin type are genetic factors and response to sun exposure and tanning habits. The Fitzpatrick scale is a numerical classification outline for determining the skin color based on a questionnaire related to an individual's genetic structure, reaction to sun exposure, and tanning habits [31]. The response to each question is measured on a scale of zero to four. The response for all the questions is added to get the ultimate score corresponding to the Fitzpatrick skin type. Skin type score was given a number from 0 to $>30$ as follows $(0$ to 7 : type I, 8-16: type II, 17-25: type III, 25-30: type IV and over 30 skin type V-VI [32].

\section{Follow-up}

After the end of the therapy, the patients were evaluated clinically every month for a period of 3 mo to detect any recurrence or complications.

\section{Assessment of clinical response to the pharmacotherapy}

Physician's opinion: Clinical evaluations were done before starting the therapy and every two weeks during the treatment by three dermatologists.

Patient's opinion and questionnaire: The patients were asked to give an accurate value for the percentage of improvement. They were asked to rate on a scale of $1-5$ (l=no response; $2=$ fair improvement; 3 =good improvement; $4=$ =ery good improvement; $5=$ excellent improvement).

Digital image analysis of standard colored photographs was used to determine the percentage of improvement of the melasma lesions.

\section{Assessment of the clinical efficacy was categorized as modified} MASI score

No response: no changes in modified MASI score at the end of the therapy. Fair response: less than $25 \%$ fall in modified MASI score. Moderate response: 25 to $50 \%$ fall in modified MASI score. Very good response: 50 to $75 \%$ fall in modified MASI score. Excellent response: more than $75 \%$ fall in the modified MASI score.

\section{Safety assessment}

It was conducted for all patients at each visit, every two weeks, after enrollment in the study. All clinical medical events, whether observed by the investigator or reported by the patient and whether or not thought to be drug-related, were considered adverse events.

\section{Follow up assessment period}

The patients were followed up and evaluated clinically and by colored photographs monthly after the end of the therapy for 3 mo to determine the degree of improvement or recurrence of the melasma lesions.

\section{RESULTS AND DISCUSSION}

\section{Observation of niosomes under a light microscope}

Photomicrographs (fig. 1) using a light microscope showed that niosomal vesicles appeared as spherical distinct and not aggregated or coalesced.
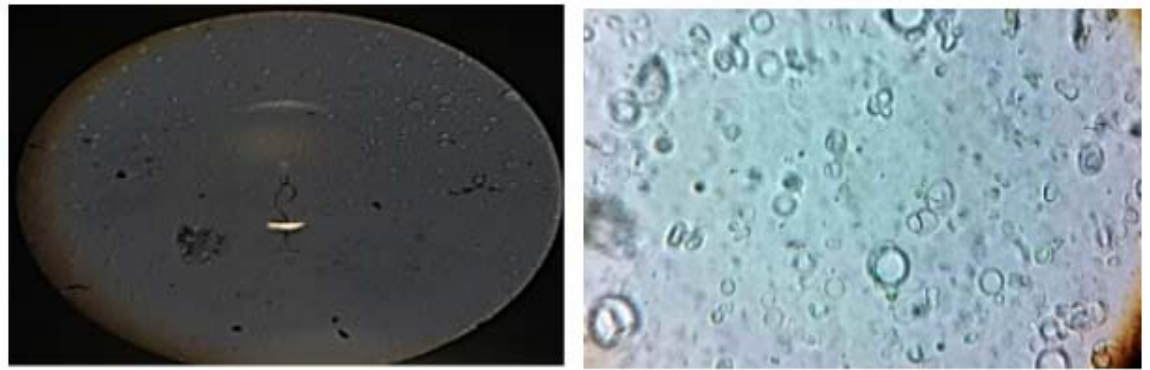

Fig. 1: Photomicrographs taken with a light microscope of the prepared niosomal formulations

\section{Entrapment efficiency}

The obtained values showed that $\mathrm{HQ}$ has been successfully incorporated into the niosomes core (fig. 2). It was obvious that
Tween 40 and Tween 60 containing formulae had higher encapsulation efficiency ( 98.59 and $96.9 \%$, respectively) compared to formulae containing Tween 20 . This can be attributed to the lower hydrophobicity.

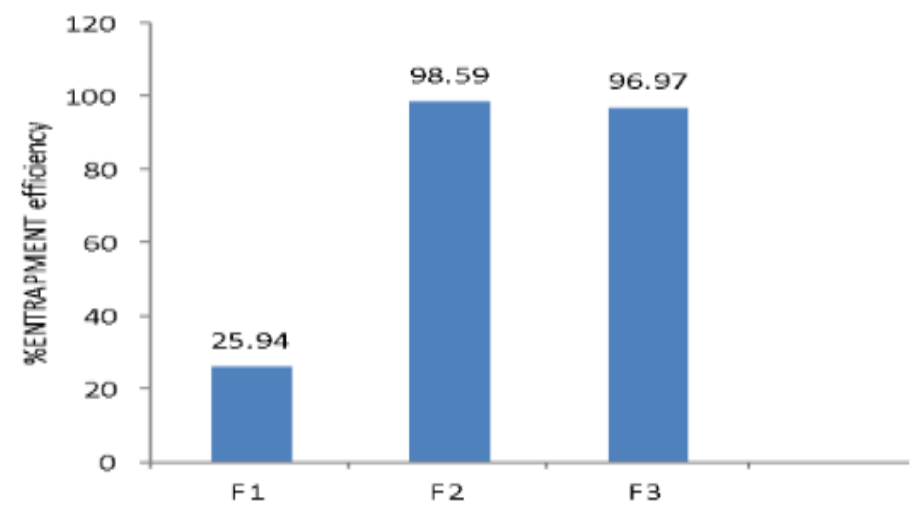

Fig. 2: Entrapment efficiency of HQ niosomes 


\section{Transmission electron microscope (TEM) microphotographs}

It gives a sub-nanometer resolution of the observed formulation. Niosomal vesicles appeared as spherical and unilamellar vesicles. The vesicles appear distinct and not aggregated or coalesced. The formulated niosomal vesicles were found to be spherical in shape, ranging from $10.4 \mathrm{~nm}$ to $32.2 \mathrm{~nm}$ in size (table 3), (fig. 3, 4).

\section{Zeta potential measurement}

The values of zeta potential for F2 and F3 are illustrated (table 3), which was found $-27 \mathrm{mV}$ and $21.9 \mathrm{mV}$ for $\mathrm{F} 2$ and $\mathrm{F} 3$, respectively. This means the physical stability of the prepared noisome. The effect of HLB values of surfactants on zeta potential could be explained in terms of surface energy, which tends to increase with an increase in HLB values towards the hydrophobicity. The increase in surface energy of the vesicles leads to increase in the values of zeta potential towards negative. As the zeta potential increases, the charged particles repel one another, and this stabilizes the system against aggregation. Systems of the zeta potential value of $\pm 30 \mathrm{mv}$ or higher are considered to be stable [20].

\section{Release of HQ from niosomes}

\section{In vitro release of $\mathrm{HQ}$ from niosomes}

The HQ loaded niosomes slowed down the release of HQ compared with the free drug solution, which released nearly $(96.8 \pm 2.6)$ of the drug within $8 \mathrm{~h}$, so there is an efficacy of the niosomal formulations in prolonging the release rate of the drug. From the release data of $\mathrm{HQ}$ from niosomes, it can be noticed that the release occurred in two distinct phases, an initial burst release, which lasted from 2-4 h, followed by a sustained but reduced release, which was maintained for at least $24 \mathrm{~h}$. This biphasic release pattern may be due to the size heterogenicity of the vesicles [33] (fig. 5).
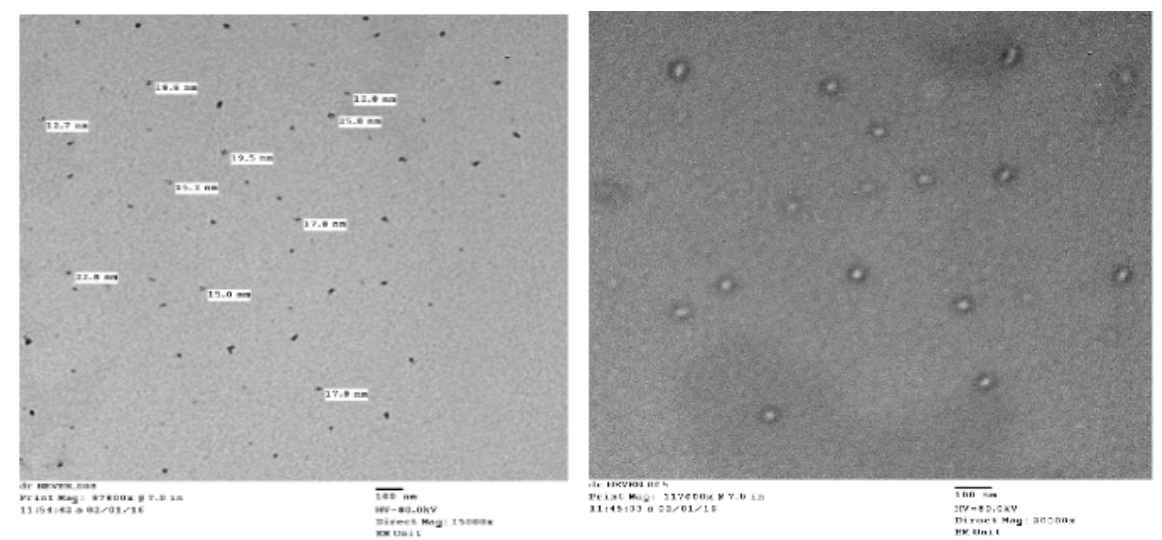

Fig. 3 TEM of F2
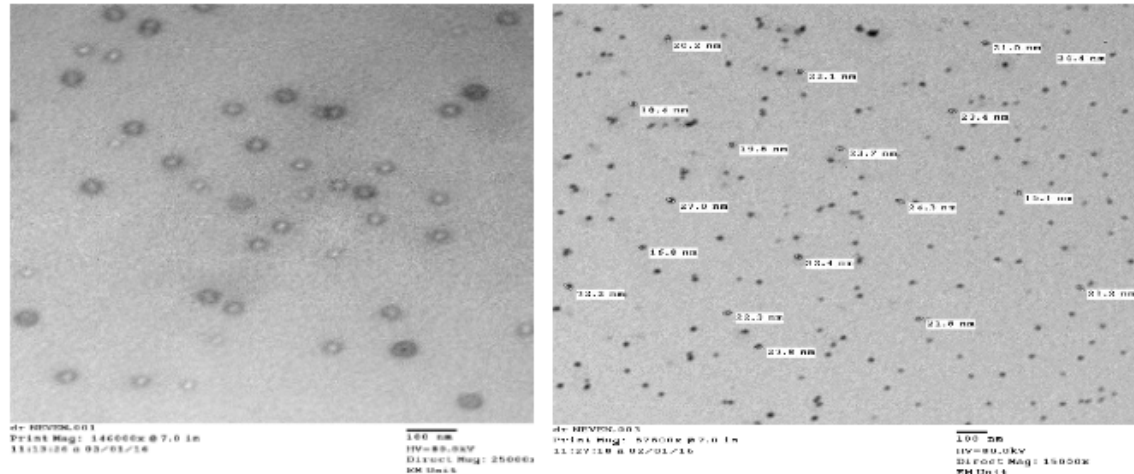

Fig. 4: TEM of F3

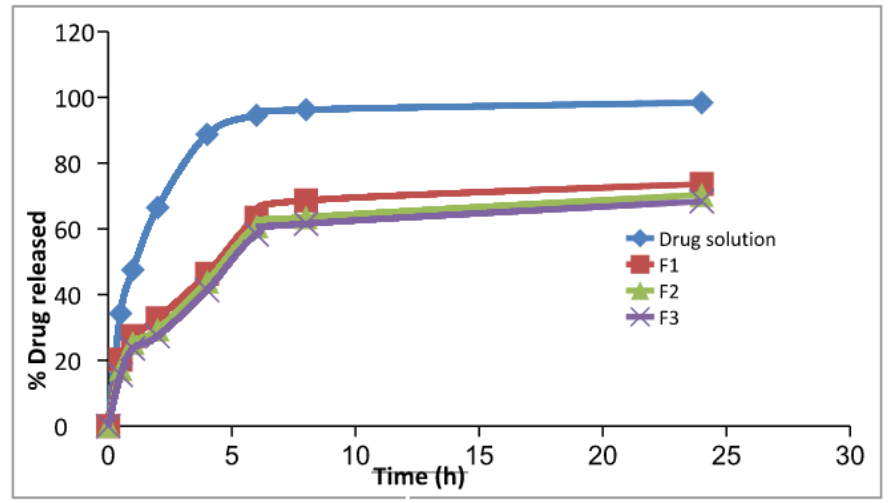

Fig. 5: In vitro release study of the prepared formulations 


\section{Color, homogeneity and texture}

All niosomal gel formulations were milky white colour. Revealed physical characters of niosomal gel formulations. F2a2, F3a2 and F2b3 were with the very good homogenous appearance and with the best smooth texture. F2a1, F2b2, F3a1 and F3b2 were with good homogenous appearance but with much-liquefied texture (could not adhere quickly on patient skin). F2a3, F2b4, F3a3, F3b4, F3b3 and F3b2 were with little homogenous appearance and with hard texture.

\section{pH values}

The $\mathrm{pH}$ values of all the prepared formulations ranged from $5.69 \pm 0.09$ to $6.92 \pm 0.06$, which probably would not produce skin irritation.

\section{Spreadability}

Spreadability of the topically applied formulation is an important property considering patient compliance. Formulations with higher spreadability values allow ease of application and thereby increased surface area available for drug permeation [34]. F2a2, F2b3 and F3a2 had a diameter between 4 and 4.3 , which indicates good spreadability. F2a1, F2b2, F3a1, F3b2 and F3b3 had a diameter between 4.4 and $4.7 \mathrm{~cm}$. F2a3, F2b4, F3a3 and F3b4 had a diameter between 3 and $3.3 \mathrm{~cm}$. These results agreed with (Yogeshwar and
Vandana, 2010) [35] who mentioned that good spreadability is above $3.5 \mathrm{~cm}$

\section{In vitro permeation studies through cellulose membrane}

Effect of concentration of Carbopol 934 as a gelling agent on the permeation of HQ from niosomal gels: The effect of Carbopol 934 concentration on the permeation of $\mathrm{HQ}$ from the formulated niosomal gels across a cellulose membrane was studied for the selection of a suitable concentration of Carbopol 934 required for producing gel with suitable consistency for topical application (fig. 6) shows the permeation of HQ from niosomal gel F2 and F3 prepared with different Carbopol 934 concentrations $(1 \%, 2 \%$ and $3 \% \mathrm{w} / \mathrm{w})$. The results indicate that the permeated amount of HQ decreased with an increasing concentration of Carbopol 934 from $1 \%$ to $3 \%$. This decrease of the permeated amount may be related to the higher resistance to drug diffusion by agreement with that previously mentioned by (El-Megrab et al., 2006), [34]. They stated that gel having a compact and close structure may have a slower release rate than one of lower consistency. It was observed that the formulations prepared with $2 \% \mathrm{w} / \mathrm{w}$ Carbopol 934 produced gel with a consistency suitable for topical application, so it was chosen to prepare all the gel formulations in this study. The same occurred in a case of CMC $\mathrm{Na}$ as shown in (fig. 7), which shows the permeation of $\mathrm{HQ}$ from niosomal gel F2 and F3 prepared with different CMC Na concentrations $(2 \%, 3 \%$ and $4 \% \mathrm{w} / \mathrm{w})$.
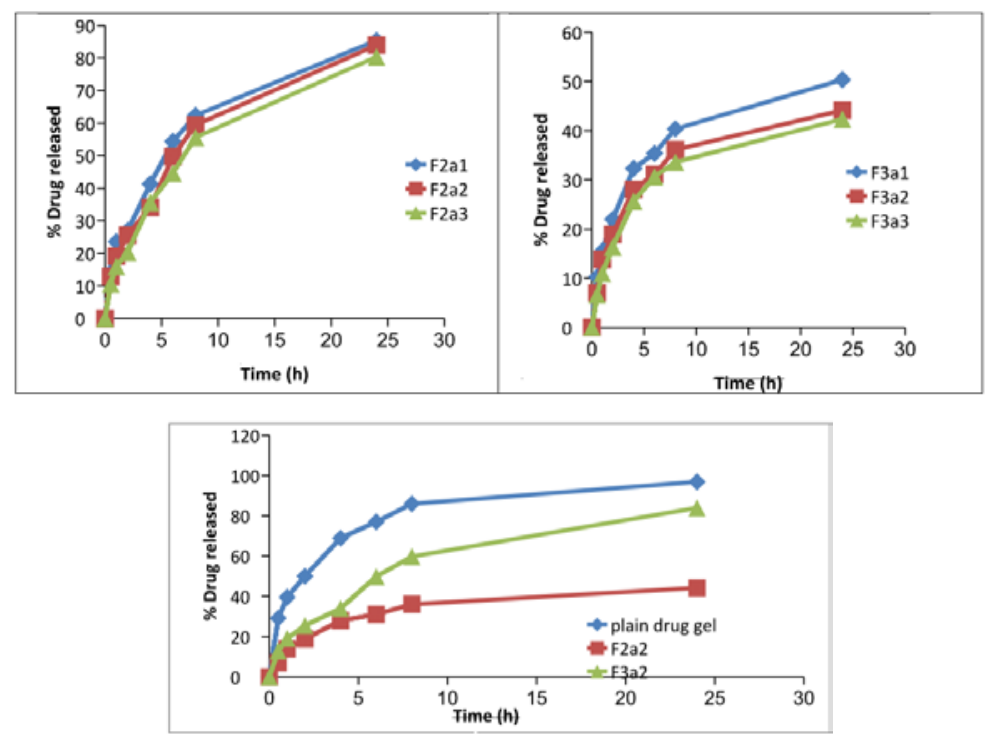

Fig. 6: The permeation of HQ from niosomal gel F2 and F3 prepared with different Carbopol 934 concentrations (1\%, 2\% and 3\% w/w)
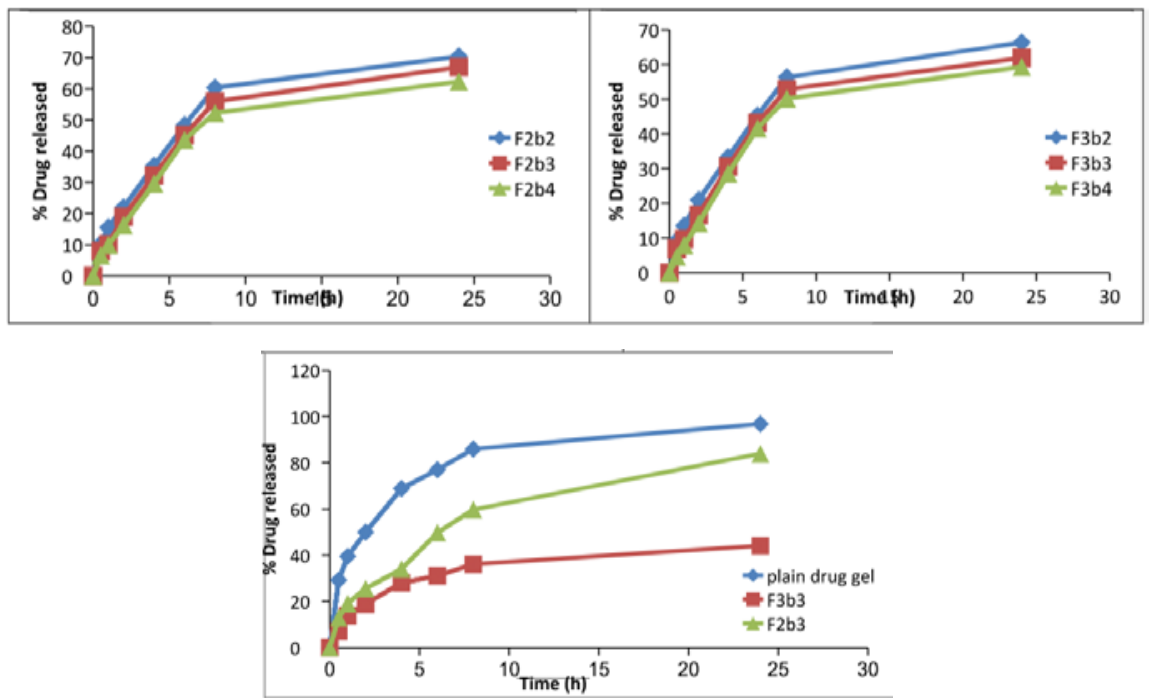

Fig. 7: the permeation of HQ from niosomal gel F2 and F3 prepared with different CMC Na concentrations (2\%, 3\% and 4\% w/w) 


\section{Accelerated stability studies of niosomal gel formulations of HQ}

The Accelerated stability studies of niosomal gel formulations of HQ were done at $4{ }^{\circ} \mathrm{C}, 25^{\circ} \mathrm{C}$ and $37^{\circ} \mathrm{C}$ and the formulations were ranked according to $t_{90}$ values as shown in (table 4 )

Melasma is procured and symmetrical hyper melanosis, ordinarily spread broadly on the malar eminence and cheek, and less regularly on the forehead and upper lip. Melasma usually appears in female patients in their 30s or 40s after pregnancy or contraceptive pills utilization, recommending that the triggering of melasma is hormonally related [36]. Melasma can be especially distressing to the patients and has appeared to affect a patient's quality of life. Since of its dermal component and liability to relapse, it is often challenging to be treated. The treatment of melasma is usually unacceptable due to the great recurrence of lesions and the absence of a definitive brightening alternative [37]. In this study, we tried to solve these problems by preparing $\mathrm{HQ}$ in niosomal gel formulations.

Before starting the pharmacotherapy, there were non-significant differences in preliminary data between the studied two groups regarding the age, sex, duration of melasma, Fitzpartic skin type, precipitating factors, dermoscopic type and pattern of melasma, and modified MASI score.

Table 4: Rank order of HQ niosomal gel formulations according to $t_{90}$ values

\begin{tabular}{lll}
\hline Formulations & t90 $_{\mathbf{9 0}}$ (days) at $\mathbf{2 0}^{\circ} \mathbf{C}$ & Rank order \\
\hline F2a2 & 97.64371 & 1 \\
F2b3 & 65.4377 & 2 \\
F3a2 & 54.36394 & 3 \\
\hline
\end{tabular}

Table 5: Preliminary data of the patients

\begin{tabular}{|c|c|c|c|c|c|}
\hline & & Group I No=30 & Group II No=30 & $T / \mathbf{X}^{2}$ & $P$-value \\
\hline \multirow[t]{2}{*}{ Age (year) } & Range & $20-60$ & $22-58$ & 0.028 & 0.867 \\
\hline & Mean & $38.37 \pm 12.25$ & $37.87 \pm 10.65$ & & \\
\hline \multirow{2}{*}{ Sex $(\%)$} & Male & 33.3 & 26.7 & 0.317 & 0.573 \\
\hline & Female & 66.7 & 73.3 & & \\
\hline \multirow[t]{3}{*}{ Duration (\%) } & $<1 \mathrm{y}$ & 13.3 & 13.3 & 0.087 & 0.957 \\
\hline & $1-5 y$ & 60.0 & 56.7 & & \\
\hline & $>5 \mathrm{y}$ & 26.7 & 30.0 & & \\
\hline \multirow{2}{*}{ Fitzpartic (\%) } & III & 40.0 & 36.7 & 0.071 & 0.791 \\
\hline & IV & 60.0 & 63.3 & & \\
\hline \multirow[t]{5}{*}{ Precipitating factors (\%) } & Sun exposure & 56.7 & 46.7 & 2.401 & 0.662 \\
\hline & Pregnancy & 0.0 & 6.7 & & \\
\hline & Hormonal medication & 13.3 & 16.7 & & \\
\hline & Positive F H & 13.3 & 13.3 & & \\
\hline & Cosmetics use & 16.7 & 16.7 & & \\
\hline \multirow[t]{3}{*}{ Type (\%) } & Epidermal & 30.0 & 26.7 & 0.087 & 0.957 \\
\hline & Mixed & 56.7 & 60.0 & & \\
\hline & Dermal & 13.3 & 13.3 & & \\
\hline \multirow[t]{2}{*}{ Pattern of melasma (\%) } & Centrofacial & 60.0 & 66.7 & 0.287 & 0.592 \\
\hline & Malar & 40.0 & 33.3 & & \\
\hline \multirow{2}{*}{ Modified MASI } & Range & $0.8-18.7$ & $0.9-18.3$ & P: 0.889 & \\
\hline & Mean & $8.41 \pm 5.82$ & $8.63 \pm 6.09$ & & \\
\hline
\end{tabular}

GroupI: applied niosomal gel, GroupII: applied Clearique ${ }^{\circledR} 2 \%$ delta pharma, Positive F H: positive family history, MASI: melasma area and severity index, age and modified MASI are presented as mean $\pm S D,{ }^{*} P<0.05$ : statistically significant difference

There was a significant difference in clinical response, complications of the therapy, duration till improvement, recurrence of melasma and modified MASI score between the two groups after the end of the therapy.

Table 6: Clinical response to the therapy, side effects, duration till improvement, and recurrence of melasma in the studied groups

\begin{tabular}{|c|c|c|c|c|c|}
\hline & & Group I No $=30$ & Group II No=30 & $\mathbf{T} / \mathbf{X}^{2}$ & $P$-value \\
\hline \multirow[t]{5}{*}{ Clinical response (\%) } & No & 0.0 & 30.0 & 13.672 & $0.008^{*}$ \\
\hline & Fair & 6.7 & 13.3 & & \\
\hline & Moderate & 6.7 & 0.0 & & \\
\hline & Very good & 56.7 & 40.0 & & \\
\hline & Excellent & 30.0 & 16.7 & & \\
\hline \multirow{2}{*}{ Duration till improvement (W) } & Range & $3-28$ & $5-30$ & 28.103 & $0.001^{* *}$ \\
\hline & Mean & $9.88 \pm 7.57$ & $19.75 \pm 6.83$ & & \\
\hline \multirow{2}{*}{ Modified MASI } & Range & $0.3-3.8$ & $0.4-18.3$ & $P: 0.011^{*}$ & \\
\hline & Mean & $1.09 \pm 0.84$ & $3.36 \pm 4.63$ & & \\
\hline \multirow[t]{5}{*}{ Complications (\%) } & No & 90.0 & 0.0 & 50.178 & $0.001^{* *}$ \\
\hline & Burning sensation & 0.0 & 20.0 & & \\
\hline & Erythema & 3.3 & 30.0 & & \\
\hline & Dryness and scaling & 6.7 & 23.3 & & \\
\hline & Pruritus & 0.0 & 26.7 & & \\
\hline \multirow[t]{2}{*}{ Recurrence of melasma } & No & 80.2 & 53.3 & 4.800 & $0.028^{*}$ \\
\hline & Yes & 20.0 & 46.7 & & \\
\hline
\end{tabular}

GroupI: applied niosomal gel, GroupII: applied Clearique ${ }^{\circledR}$ 2\% delta pharma, MASI: melasma area and severity index, duration till improvement and modified MASI are presented as mean \pm SD, ${ }^{*} P<0.05$ : statistically significant difference, ${ }^{* *} P<0.001$ : a highly statistically significant difference. 
In the current study, assessment of the clinical response of the therapy was done by physicians' opinions, patients and digital photographs every $4 \mathrm{w}$ and modified MASI score at base and at the end of the therapy.

In this research, excellent results occurred in $23.3 \%$ of the patients, very good in $48.8 \%$, good in $3.3 \%$, fair results in $10 \%$ and no response in $15 \%$ of the patients. Excellent and very good responses were occurred predominantly in group I. The best response to the therapy was in epidermal type than in mixed and dermal types in groups I and II. This may be explained by the presence of melanin in epidermal melasma in superficial epidermal cells, which is easily penetrated by the topical therapy and replaced more often, but in dermal melasma, melanin is engulfed by melanophages deep in the dermis and require a high penetration influence of the topical therapy. As well as the best response was in patients with melasma duration $<5$ y than those with melasma duration $>5 \mathrm{y}$ in groups I and II. This may be explained by the transformation of epidermal melasma to mixed or dermal type on long duration of the disease and may be due to the cumulative effect of sun exposure.

Our results are in accordance with a comparative study of HQ and kojic acid in the treatment of Melasma by (Gajjala et al., 2016) [38]. This study clearly demonstrated a positive effect of kojic acid cream $2 \%$ on melasma lesions, with improvements of $10 \%, 22 \%$ and $32 \%$, seen at the end of the first, second and third month, respectively. In contrast, the positive response to treatment with HQ cream $2 \%$ at the end of the first, second and the third month were $7 \%, 24 \%$ and $53 \%$, respectively.

Regarding to the duration of therapy till achievement of the clinical improvement, in the niosomal gel group it ranged from 3-28 w with a mean $9.88 \pm 7.57$ and $5-30 \mathrm{w}$ with a mean $19.75 \pm 6.83$ in the commercial product group that revealed a highly significant decrease in the period needed to attain clinical efficacy in the group used niosomal gel $(* * \quad p<0.001)$. These results are consistent with those of (Hadded et al., 2003) [39] whose patients improved after 12 w of treatment with $\mathrm{HQ}$ alone.

Modified MASI score improved significantly in both groups after the therapy compared to before the therapy as well as there was a significant decrease in modified MASI score in the niosomal group after treatment in comparison to the commercial group $* P<0.05$. In a recent study by (Samreen Rafi et al., 2017) [40] who compared the efficacy of topical HQ $2 \%$ and oral tranexamic acid $500 \mathrm{mg}$ daily in patients of melasma. Their results showed that in HQ group, the mean MASI at baseline was $40.42 \pm 4.74$ and at the end of 8-week therapy, it reduced to $13.33 \pm 3.29$; there was $67.02 \pm 9.51 \%$ reduction in the mean MASI score $\left({ }^{*} p<0.05\right)$ that in agreement with our results.

Safety assessment: In group I, $90 \%$ of the patients experienced no complication and one patient that represents $3.3 \%$ experienced mild erythema (duration of erythema ranged between 7 to $14 \mathrm{~d}$ ). This was resolved by application of a cold compress and a bland emollient and $6.7 \%$ experienced dryness and scaliness at the site of application after $4 \mathrm{w}$ of starting the therapy which resolved by a bland emollient. In group II, 30\% experienced erythema, 23.3\% experienced dryness and scaliness and $26.7 \%$ experienced pruritus at the site of application, which resolved gradually in $7 \mathrm{~d}$. $20 \%$ of the patients experienced a severe burning sensation, which resolved spontaneously. These results showed a high significant reduction in side effects in the niosomal group $\left.{ }^{* *} p<0.001\right)$. In the previous study by (Gajjala et al., 2016) [38], 53\% of patients who had melasma lesions on the left side treated by HQ cream $2 \%$ complained about erythema and burning sensation side effects. On the other hand, only $26 \%$ of those treated by kojic acid (on the right side of the face) cream did so. The lower side effects in the current study in patients treated with niosomal gel may be due to the prevention of direct contact of skin with $\mathrm{HQ}$ as it was encapsulated in niosomes. Also the presence of surfactant, co-surfactant and carbopol in our formulae caused the demulcent and cold sensation at the site of application.

In this study, the patients were evaluated monthly for 3 mo after the end of depigmentation therapy. The recurrence of melasma had occurred in 6 patients $(20 \%)$ in the niosomal gel group and 14 patients $(46.7 \%)$ in the commercial product group that revealed a

statistically significant decline in the reappearance of melasma in niosomal gel group $\left({ }^{*} p<0.05\right)$. Sun exposure was the most important precipitating factor related to recurrence, which suggests the major role of ultra-violet rays in the etiology of melasma lesions.
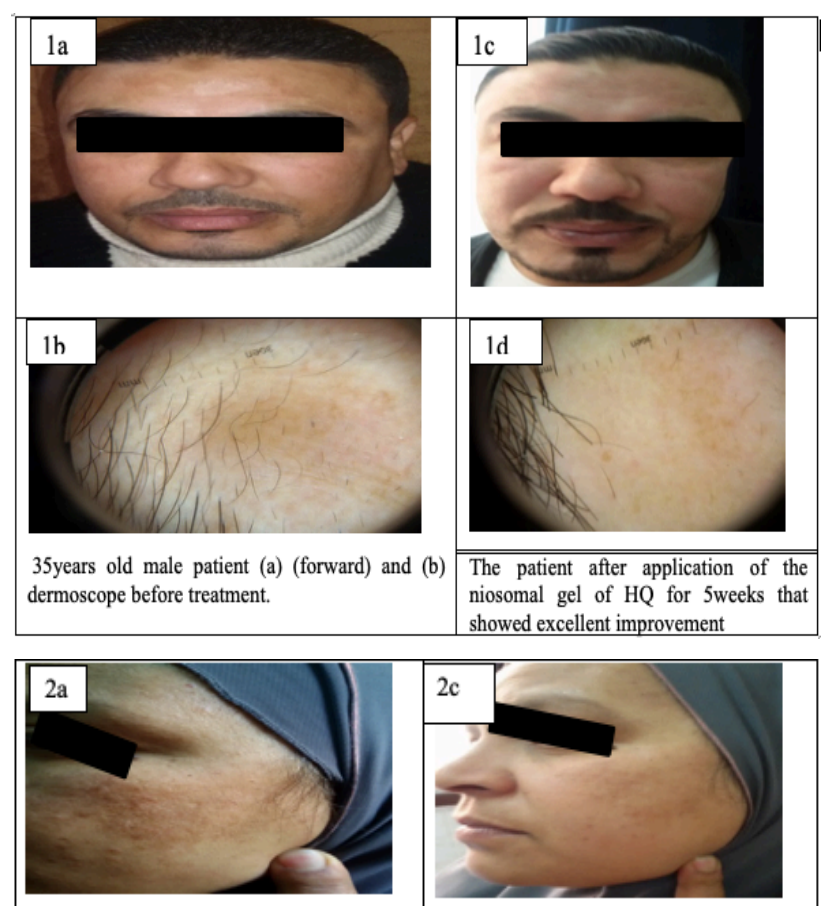

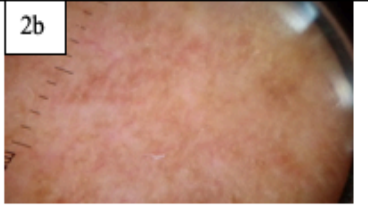

Photo2: 51years old female patient (a) (left) and (b) dermoscope before treatment.
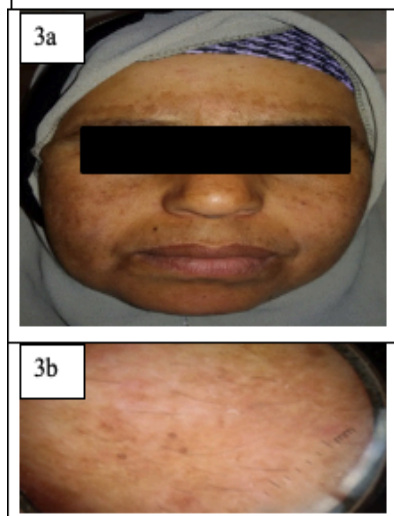

Photo 3:48 years old female Patient (a) (forward) and (b) dermoscope before treatment.

Fig. 8: Patients before and after treatment

\section{CONCLUSION}

The current work succeeded in proving that incorporating HQ in niosomal gel improves its therapeutic effect regarding clinical efficacy, shorter duration of treatment, nearly absence of side effects and lesser recurrence. Niosomal gel of $\mathrm{HQ}$ also demonstrated that it has better patient compliance than Clearique $2 \% \AA$ delta pharma since the second one causes erythema, pruritus and burning sensation at the site of application. 


\section{FUNDING}

Nil

\section{AUTHORS CONTRIBUTIONS}

All the authors have contributed equally.

\section{CONFLICT OF INTERESTS}

The authors declare that there are no conflicts of interest.

\section{REFERENCES}

1. Jagannathan M, Sadagopan K, Ekkarakudy J, Anandan H. Clinicoepidemiological study of patients with melasma in a tertiary care hospital. A prospective study. Int J Sci Study 2017;4:117-20.

2. Achar A, Raithi SK. Melasma: a clinico-epidemiological study of 312 cases. Indian J Dermatol 2011;56:380-2.

3. Lyndle CB, Kraft JN, Lynde CW. Topical treatments for melasma and post-inflammatory hyperpigmentation. Skin Thera Lett 2006;11:1-6.

4. Anisha BP. Postinflammatory hyperpigmentation. Review of pathogenesis, prevention, and treatment. Pigment Int 2014;1:59-69.

5. Jiao J. Polyoxy ethylated nonionic surfactants and their applications in topical ocular drug delivery. Adv Drug Delivery Rev 2008;60:1663-73.

6. Madhav NV, Saini A. Niosomes a novel drug delivery system. Int J Res Pharm Chem 2011;1:498-511.

7. Nagalakshmi S, Damodharan N, Thanka J, Seethalakshmi S. Niosomes in ocular drug delivery system. A review of magic targeted drug delivery. Int J Pharm Sci Rev Res 2015;32:61-6.

8. Kumar BS, Krishna R, Lakshmi PS, Vasudev DT, Nair SC. Formulation and evaluation of niosomal suspension of cefixime. Asian J Pharm Clin Res 2017;10:194-201.

9. Kopermsuba P, Mayena V, Warin C. Potential use of niosomes for encapsulation of nisin and EDTA and their antibacterial activity enhancement. Food Res Int 2011;44:605-12.

10. Paul S, Mondol R, Ranjit S, Maiti S. Antiglaucomatic niosomal system: recent trend in ocular drug delivery research. Int J Pharm Pharm Sci 2010;2:15-8.

11. Draelos ZD. Skin lightening preparations and the hydroquinone controversy. Dermatol Ther 2007;20:308-13.

12. Céline $C$, Laurence C. Overview of skin whitening agents: drugs and cosmetic products. Cosmetics J 2016;3:1-16.

13. Sharma B, Sharma A. Future prospect of nanotechnology in development of anti-aging formulations. Int J Pharm Pharm Sci 2012;4:57-66.

14. Agarwal R, Katar OP, Vyas SP. Preparation and in vitro evaluation of liposomal/niosomal delivery systems for antipsoriatic drug dithranol. Int J Pharm 2001;228:43-52.

15. US Patent-Meybeck, United States patent: patent number 5279834;1994.

16. Manosroi A, Y Vongtrakfui P, Manosroi J, Sakai H, Sugawara F, Yuasa $\mathrm{M}$, et al. Characterization of vesicles prepared with various non-ionic surfactants mixed with cholesterol. Colloid Surf B 2003;30:129-38.

17. Bansal S, Aggarwal G, Chandel P, Harikumar SL. Design and development of cefdinir niosomes for oral delivery. Pharm Bioallied Sci 2013;5:318-25.

18. Mokhtar M, Amour OA, Hammed MA, Megrab NA. Effect of some formulation parameters on flurbiprofen encapsulation and release rates of niosomes prepared from proniosomes. Int J Pharm 2008;361:104-11.

19. Akhilesh D, Prabhakara P. Development and investigation of niosomes of brimonidine tartrate and timolol maleate for the treatment of glaucoma. Int J PharmTech Res 2014;6:942-50.
20. Sezgin Bayinder Z, Yoksel N. Investigation of formulation variables and excipient interaction on the production of niosomes. AAPS PharmSciTech 2012;13:826-35.

21. Ruckmani K, Sankar V, Sivakumar M. Tissue distribution, pharmacokinetics and stability studies of zidovudine delivered by niosomes and proniosomes. J Biomed Nanotechnol 2010;6:43-51.

22. Abdallah AM. Controlled release formulations of certain antiinflammatory drugs. M Sc Zagazig, University; 2005.

23. Larrucea E, Arellano A, Santoyo S, Ygartua P. Interaction of tenoxicam with cyclodextrins and its influence on the in vitro percutaneous penetration of the drug. Drug Dev Ind Pharm 2001;27:251-60.

24. Fergani AM. Topical permeation characteristics of diclofenac sodium from Na CMC gels in comparison with conventional gel formulation. Drug Dev Ind Pharm 2001;27:1083-97.

25. Shivhare UD, Jain KB, Mathur VB, Bhusari KP, Roy AA, Sharad. Formulation development and evaluation of diclofenac sodium gel using water-soluble polyacrylamide polymer. Digest J Nanomat Biostruct 2009;4:285-90.

26. Shinde U, Pokharkar S, Modani S. Design and evaluation of microemulsion gel system of nadifloxacin. Indian J Pharm Sci 2012;74:237-47.

27. Charyulu RN, Harish NM, Mohammed GA, Prabhu P, Amith KS, Subrahmanyam EV. Formulation and in vitro evaluation of in situ gels containing secnidazole for vaginitis. Yakugakuzasshi 2009;129:569-74.

28. Sammour OA, Marzouk MA, Ramadan AA, Shawky SM. In vitro permeation and pharmaco-dynamic properties of gel formulations containing tenoxicam entrapped noisome. J Life Med 2013;1:1-10.

29. Pandya AG, Hynan LS, Bhore R. Reliability assessment and validation of the melasma area and severity index (MASI) and a new modified MASI scoring method. J Am Acad Dermatol 2011;64:78-83.

30. Majid I, Haq I, Imran S, Keen A, Aziz K, Arif T. Proposing melasma severity index: a new, more practical, office-based scoring system for assessing the severity of melasma. Indian J Dermatol 2016;61:39-44.

31. Eilers S, Bach DQ, Gaber R, Blatt $\mathrm{H}$, Guevara Y, Nitsche $\mathrm{K}$, et al. Accuracy of self-report in assessing fitzpatrick skin phototypes I through VI. JAMA Dermatol 2013;149:1289-94.

32. Sachdeva S. Fitzpatrick skin typing. Applications in dermatology. Indian J Dermatol Venereol Leprol 2009;75:93-6.

33. Popli H, Nair MS. Niosomal delivery of tenoxicam. Ind J Pharm Sci 1996;58:163-6.

34. El-Megrab NA, Hanan M, El-Nahas HM, Balata GF. Formulation and evaluation of meloxicam gels for topical administration. Saudi Pharm J 2006;14:155-62.

35. Yogeshwar GB, Vandana BP. Formulation of meloxicam gel for topical application: in vitro and in vivo evaluation. Acta Pharm 2010;60:153-63.

36. Perez M, Luke J, Rossi A. Melasma in latin americans. J Drugs Dermatol 2011;10:517-23.

37. Katiyar S, Saify K, Rai M. A systemic review on melasma. Int J Curr Bio Med Sci 2011;1:63-8.

38. Gajjala S, Ali SY, Chowdary N, Harshini S. The comparative study of hydroquinone and kojic acid in the treatment of melasma. IOSR J Dental Med Sci 2016;15:1-5.

39. Haddad AL, Matos LF, Brunstein F, Ferreira LM. A clinical prospective, randomized, double-blind trial comparing skin whitening complex with hydroquinone vs. placebo in the treatment of melasma. Int J Dermatol 2003;42:153-6.

40. Samreen R, Iftikhar U, Rani Z, Hussain I. Comparison of efficacy and safety of topical hydroquinone $2 \%$ and oral tranexamic acid $500 \mathrm{mg}$ in patients of melasma. J Pakistan Assoc Dermatol 2017;27:204-13. 